\title{
Voix plurielles
}

Revue de l'Association des professeur.e.s de français des universités et collèges canadiens (APFUCC)

\section{Vermette, Katherena. femme-rivière et Sylvain, Véronique. Premier quart}

\section{Bénédicte Lung}

Volume 17, numéro 1, 2020

URI : https://id.erudit.org/iderudit/1069231ar

DOI : https://doi.org/10.26522/vp.v17i1.2492

Aller au sommaire du numéro

Éditeur(s)

Association des professeur.e.s de français des universités et collèges canadiens (APFUCC)

ISSN

1925-0614 (numérique)

Découvrir la revue

Citer ce compte rendu

Lung, B. (2020). Compte rendu de [Vermette, Katherena. femme-rivière et Sylvain, Véronique. Premier quart]. Voix plurielles, 17(1), 225-226.

https://doi.org/10.26522/vp.v17i1.2492 
Vermette, Katherena. femme-rivière. Tr. de l'anglais Rose Després. Sudbury : Prise de parole, 2019. $116 \mathrm{p}$.

\section{Sylvain, Véronique. Premier quart. Sudbury : Prise de parole, 2019. 105 p.}

Katherena Vermette, auteure métis chevronnée, et Véronique Sylvain, dans son premier recueil, ont récemment été publiées chez Prise de parole : femme-rivière (traduit de l'anglais par Rose Després) pour la première et Premier quart pour la seconde. Les deux ouvrages s'inscrivent dans le lieu d'origine et dans le passé collectif d'un Nord isolé, tout en insistant sur l'expérience personnelle qui appartient à la contemporanéité moderne. Dans femme-rivière, la poète déclare : « je suis Métisse / partie de toutes les parties / mon peuple savait / comment faire fonctionner tout ça ». Proposant « Une autre histoire », elle revendique une tradition « Métis Sage » et le métissage de ses origines indigènes et européennes profondément enracinés dans les paysages et les cultures indigènes du Manitoba, mais minorisés et largement ignorés durant la colonisation. Comme le précise une citation en exergue, « tout est politique » dans le recueil. Ainsi, dans « rivière noire », Vermette visite la Première nation de Little Black River, au nord de Winnipeg, où elle écoute « les langues brodées / en récits », « ficelées / de mots sacrés », « nouées de / longs verbes / qui désirent / être compris ». Dans « rivière rouge », elle suit le cours d'eau qui, né « entre / deux territoires / Dakota / Anishnaabe », coule vers le nord jusqu'au lac Winnipeg. Cette rivière, écrit-elle, « est une femme / [...] brillante », « draguée / puis trainée », « s'entortillant vers le nord ». Traversant villes et prairie, elle est urbaine et polluée tout aussi bien qu'ancestrale et source de vie. A tout instant, femme-rivière recueille les pépites de savoirs et d'histoire indigènes tout en nous rappelant le poids de la réalité coloniale.

Premier quart de Véronique Sylvain, contrairement au recueil énergique et fier de Vermette, se conçoit dans une douleur « solitaire / entourée / de conifères / endormis ». S'appuyant sur la littérature franco-ontarienne qu'elle découvre pendant ses études à Sudbury, la poète, à présent établie à Ottawa, définit sa nordicité d'origine en termes qui rappellent la ballade désespérée d'un Franco-Ontarien qui, pour gagner sa vie, s'en va pour la grande ville, où il perd sa langue et tout son être dans un poème bien connu de Patrice Desbiens. Quelques décennies plus tard, dans le Nord francophone de Sylvain, les mines y offrent « un salaire / plus intéressant / qu'une vie » et « les vêtements / délabrés / épousent / les cordes / à linge ». Pour vivre, il faut emprunter « la langue / de l'Autre » et « se heurter / au silence ». Sensible aux « allures cimetières / d'un monument / de la francophonie », la poète adapte, pour conclure, le slogan « Nous sommes, 
nous serons » scandé par les manifestant.es franco-ontarien.nes contre le gouvernement provincial en 2018 afin de protéger l'enseignement de la langue minoritaire : «je serai / [...] résistante / aux intempéries », une « note / d'accordéon / qui déchire / le ciel ». Comme chez Vermette, la poésie de Sylvain est géographique et historique, une voix féminine intime qui porte l'expérience de populations trop longtemps négligées.

Bénédicte Lung 